\title{
Editorial
}

\section{Convenciones sociales y sus modulaciones}

\section{Sérgio Carrara ${ }^{1}$}

> scarrara1@gmail.com

\section{Silvia Aguião²}

> saguiao@gmail.com

\section{Claudia Mora ${ }^{1}$}

> claudiamoraca@hotmail.com

\section{Bruno Zilli}

> brunozilli@gmail.com

${ }^{1}$ Universidade do Estado do Rio de Janeiro Instituto de Medicina Social

Departamento de Políticas e Instituições de Saúde Rio de Janeiro, Brasil

${ }^{2}$ Centro Latino Americano em Sexualidade e Direitos Humanos - CLAM Rio de Janeiro, Brasil

Copyright @ 2017 Sexualidad, Salud y Sociedad - Revista Latinoamericana. This is an Open Access article distributed under the terms of the Creative Commons Attribution License (http creativecommons.org/licenses/by/4.0/), which permits unrestricted use, distribution, and reproduction in any medium, provided the original work is properly cited. 


\section{Editorial}

\section{Convenciones sociales y sus modulaciones}

Más allá de la diversidad contextos nacionales abordados -Argentina, Brasil, Colombia y Panamá- los artículos de este número proponen contribuciones significativas para la reflexión sobre el modo cómo el género y la sexualidad se articulan con temas como violencia, salud y ciudadanía.

Bajo la perspectiva de las epistemologías feministas, las relaciones entre violencia y género son exploradas en dos distintos contextos nacionales a través de las investigaciones de Álvarez y Arroyo, y de Barreto Ávila. La primera nos presenta la naturalización de las violencias en los relacionamientos conyugales y en los espacios de sociabilidad, desde el punto de vista de mujeres y adolescentes de la ciudad de Medellín. Considerando los efectos del conflicto armado interno de Colombia -particularmente, en términos de la exacerbación de la concepción de los cuerpos femeninos como "territorios de disciplinamiento y control"- el análisis se enfoca en las desigualdades identificadas por las propias mujeres y adolescentes en su cotidiano. A pesar de la reproducción de estereotipos de género (ilustrado por las cargas de trabajo doméstico, las prohibiciones en las actividades de ocio y juego, limitaciones simbólicas y estructurales en el acceso a la educación y, finalmente, las prácticas violentas de sus parejas) las autoras observan las resistencias y empoderamiento de las mujeres que cuestionan los estereotipos y atribuyen nuevos sentidos a las relaciones conyugales y familiares. La investigación problematiza las narrativas que transversalizan la gramática emocional del miedo y de la dependencia, teniendo como horizonte la construcción de "relaciones más pacíficas, equitativas y democráticas", muy lejos del proceso de resolución del conflicto armado vigente.

Por otra parte, Barreto Ávila reflexiona sobre violencia de género en el contexto universitario, a partir de una denuncia de violación ocurrida en la Universidad Nacional Autónoma de México, que se volviera un caso emblemático. La argumentación principal se teje en torno del accionamiento del "testimonio", como forma de reparación individual y colectiva, en situaciones en que las respuestas jurídicas y/o institucionales insisten en accionar elementos de culpabilización y estigmatización de la víctima. El artículo pone de relieve las disputas existentes en el ámbito de la (re)significación de antiguas categorías jurídicas relativas a la violación. En diálogo con trabajos de Boltanski (1993), Jimeno (2010) y Ross (2000), entre otros, la autora explicita también las dinámicas provocadas por la repercusión del caso en diferentes espacios e instancias, a través de hacer público y colectivizar el testimonio del sujeto denunciante. A través de un lenguaje político-emocional, la ganancia de empatía y la legitimación de la denuncia producen efectos de desplazamientos diversos. 
Teniendo como telón de fondo la coyuntura más amplia del fortalecimiento de fuerzas conservadoras en América Latina, tanto a nivel local, como en el ámbito nacional, dos artículos contribuyen a la reflexión sobre el proceso más general de reconocimiento de la ciudadanía LGBT en la región. Apoyados en fuentes documentales diversas - producciones académicas, documentos gubernamentales y noticias divulgadas en portales virtuales-Aragusuku y Lopes realizan una lectura de las iniciativas dirigidas a la población LGBT en el ámbito de políticas públicas en el estado brasileño de Mato Grosso, entre los años 2007 a 2017, relacionándolas al escenario político más general del Estado brasileño y a la actuación de los movimientos LGBT locales. Galindo y colaboradoras presentan las vivencias de habitantes de la ciudad de Tunja, Colombia, caracterizada por el conservadurismo y donde tradicionalmente la Iglesia Católica ejerce especial control. Considerado como "territorio tabú para la expresión de la diversidad sexual", la ciudad, de tamaño medio, es escenario de tensión entre la tradición y la ruptura. Así, por medio de las voces de las personas entrevistadas, son retratadas escenas de homofobia en los ámbitos público y familiar, pero que tienen como contrapunto narrativas de participación social y política de la comunidad LGBT en los pocos espacios civiles y de sociabilidad ya constituidos.

Las diferentes formas de "habitar la norma" (Butler, 1999; 2003) o la convención social relativa a la masculinidad surgen con especial énfasis en cinco artículos de este número. Etnografiando "fiestas de orgía para hombres" realizadas en Río de Janeiro, la reflexión de Barreto dialoga con una serie de investigaciones que, en los últimos años, han lanzado una mirada antropológica sobre la sexualidad y sus expresiones consideradas abyectas (ver, entre otros, Pelúcio, 2009; Díaz-Benítez, 2015). El autor presenta un contexto en que la homosexualidad surge como una suerte de variación de la propia masculinidad. Aborda cuestiones conectadas al deseo, al erotismo y la performance de una virilidad que, representada en la figura del "macho", establece quién puede o no participar en ese espacio.

Enfocada en documentación referente a procesos de la justicia militar artentina, entre los años 1960 a 1980, Fernández explora simultáneamente los abordajes para cohibir la homosexualidad, por medio de su codificación como "delito contra el honor militar"; y las brechas reglamentarias y conceptuales por las cuales relaciones afectivo-sexuales entre hombres perduraban y, en algunos contextos, hasta se justificaban. Por otro lado, Navone analiza las representación sobre la masculinidad de hombres con deficiencia física, vehiculadas por discursividades producidas en torno del escritor Nick Vujicic y de Josito, conocido actor porno con deficiencia física, además de otros materiales, procedentes tanto de producciones culturales cuanto de saberes médicos. La discusión se sitúa en la intersección entre los estudios de género, la teoría queer, los estudios sobre deficiencia (disability studies) y la teo- 
ría crip. El autor desenvuelve una crítica a la producción de una "pedagogía para la normalidad", constituida tanto en relación a los sentidos accionados sobre el cuerpo con deficiencia, cuanto a la normatividad heterosexual masculina.

En su artículo, Passamani y Saggese abordan el documental “Bailão” de 2009, cuyo foco es un tradicional espacio de sociabilidad masculina de la ciudad de São Paulo. El análisis se centra en la intersección entre homosexualidad masculina y generación, describiendo las intensas transformación por las que pasa la experiencia de los sujetos que han frecuentado el espacio a lo largo de las últimas décadas y que componen el cuadro más amplio de transformación a partir del cual surge una gaycidad, como propone el sociólogo argentino Ernesto Meccia (2011).

Finalmente, también en la estela de convenciones relativas a la masculinidad, tenemos el instigador texto de Madi Dias, basado en su largo trabajo de campo entre el pueblo Guna de Panamá. En él, el autor aborda la experiencia o la perspectiva de las omeggids. Tratadas de modo peyorativo en la literatura antropológica como "berdaches", las personas two spirit, como las omeggids gunas vienen provocando la reflexión (más frecuentemente, la curiosidad) de viajeros y etnógrafos desde el "descubrimiento" del Nuevo Mundo. Antes que insistir -como hicieron autores clásicos (Clastres, 1978) - sobre el modo particular cómo la pretendida "homosexualidad" de esas personas se encuentra socialmente integrada en esos pueblos, Madi Dias lanza una mirada renovada y profundamente involucrada sobre esa experiencia, y accionando las elaboraciones foucaultianas alrededor de la amistad y de las teorías feministas sobre el cuidado, reconsidera procesos contemporáneos de ciudadanización de la diversidad sexual y de género.

Como manifestamos al inicio, parte importante de este número está dedicado a las conexiones entre género, sexualidad y salud. La temática se encuentra en el artículo de Ricardo Coitinho Filho, y su pesquisa etnográficaa de redes de sociabilidad de jóvenes que viven con VIH/SIDA en Río de Janeiro. Los resultados de su trabajo se concentran en el análisis de un evento conocido en esa red como "encuentro", que circunscribe espacios de sociabilidad y de acogida. En diálogo con el aporte de la antropología de las emociones, el autor analiza la dimensión política de las gramáticas emocionales presentes en narrativas sobre el sufrimiento.

Además del artículo de Coitinho Filho, este número de Sexualidad, Salud y Sociedad publica el primero de los dossiers especiales sobre VIH/SIDA en Brasil, previstos para 2018. La preparación de ambos dossiers se justifica en el interés de investigadores e investigadoras, de diferentes disciplinas de las ciencias humanas y sociales -salud colectiva, sociología, antropología, psicología social- por revigorizar los debates y contribuciones sobre la epidemia, generados desde una perspectiva sociocultural. Las prácticas y políticas de combate al Sida, en la última década, han estado marcadas por cambios en el perfil epidemiológico, que afecta 
particularmente a jóvenes y a "hombres que tienen sexos con hombres", y por la apuesta del gobierno brasileño en un abordaje basado en la llamada "prevención combinada" (Brasil, 2017). Dicho abordaje presupone el uso de insumos de corte biomédico -como las profilaxis pre y post exposición-, sumado a la articulación entre intervenciones biomédicas, estructurales y comportamentales. Sobre el avance de las alternativas biomédicas de prevención es preciso reconocer que estamos frente a una coyuntura de debilitamiento de la respuesta social a la epidemia, y de reducción progresiva de espacios para vocalizar las cuestiones de género y sexualidad que la atraviesan.

El dossier que publicamos deriva de las discusiones que tuvieron lugar en el Grupo de Trabajo "Articulações entre gênero, sexualidade e outras diferenças no cotidiano da prevenção de HIV/aids: olhares a partir de processos de mudança social”, organizado en el ámbito del $11^{\circ}$ Fazendo Gênero, en Florianópolis, entre el 30 de julio y el 4 de agosto de 2017. Regina Facchini (Pagu/Unicamp), Thiago F. Pinheiro (Nepaids/USP) y Gabriela J. Calazans (Nepaids/USP), sus organizadores, presentan un conjunto de trabajos cuyo énfasis recae sobre la relación de la epidemia con la producción de diferencias sociales, sea en relación a la distribución epidemiológica, o en relación a la construcción discursiva de la enfermedad.

El segundo dossier - que será publicado en el próximo número de la Revista-, estará organizado por Monica Franch (UFPB), Ivia Maksud (Fiocruz), Felipe Rios (UFPE) y Claudia Mora (IMS/UERJ), y reúne investigaciones debatidas en el Grupo de Trabajo "DST/HIV/AIDS, Políticas e Subjetividades", organizado en el ámbito de las ediciones de 2013 y 2016 del Congresso Brasileiro de Ciências Sociais e Humanas em Saúde (Abrasco). El segundo dossier del año presenta pesquisas que abordan las interacciones sociales y sexuales que envuelven a personas que viven y conviven con el VIH/SIDA, y las percepciones de los actores sociales sobre las nuevas tecnologías de test y prevención.

Así, Sexualidad, Salud y Sociedad pretende, con la publicación de dos dossiers temáticos, contribuir a bosquejar un panorama de la cuarta década de epidemia de VIH/SIDA, enfocando los deseos, identidades y activismos en Brasil. 


\section{Referencias bibliográficas}

BOLTANSKI, Luc. 1993. La Souffrance à Distance. Morale Humanitaire, Médias et Politique. Paris: Éditions Métaillé. 288 pp.

BUTLER, Judith. 2003. Problemas de gênero: feminismo e subversão da identidade. Rio de janeiro: Civilização Brasileira.

BUTLER, Judith. 1999. "Corpos que pesam: sobre os limites discursivos do 'sexo'”. In: LOURO, Guacira Lopes (Org.). O corpo educado: pedagogias da sexualidade. Belo Horizonte: Autêntica, p. 151-172.

CLASTRES, Pierre, 1978. O arco e o cesto. Pierre Clastres, a Sociedade contra o Estado. São Paulo, Brasiliense, 119-143.

DÍAZ-BENÍTEZ, María Elvira. "O espetáculo da humilhação, fissuras e limites da sexualidade”. Mana [online]. 2015, vol.21, n.1, p.65-90. Disponível em: http://dx.doi. org/10.1590/0104-93132015v21n1p065

JIMENO M. 2010. "Emoções e política: a vítima e a construção de comunidades emocionais". Mana. Vol. 16, no 1, p. 99-121. Disponible en: https://dx.doi.org/10.1590/ S0104-93132010000100005

MECCIA, Ernesto. 2011. Los últimos homosexuales: Sociología de la homosexualidad y gaycidad. Buenos Aires: Gran Aldea.

MINISTÉRIO da Saúde. 2017. Diretrizes Nacionais de Prevenção Combinada em HIV/ Aids http://www.aids.gov.br/pt-br/gestores/organizacao-dos-servicos/diretrizes-nacionais-de-prevencao-combinada-em-hivaids Acesso: 27.01.2018

PELUCIO, Larissa. 2009. Abjeção e Desejo - uma etnografia travesti sobre o modelo preventivo de Aids. 1. ed. São Paulo, SP: Editora Annablume.

ROSS, F., C. 2000. Bearing Witness: Women and the South Africa Truth and Reconciliation Commission. Thesis of doctor Philosophy. University of Cape Town. Disponible en: https://open.uct.ac.za/handle/11427/361 [consultado el 10.06.18]. 